\title{
Need of Computational Intelligence for Post Graduate Students as an Academic Learning
}

\author{
Ayesha Saleem ${ }^{1}$, Usman Saleem ${ }^{2}$, Somia $\mathrm{Ali}^{3}$ and Misbah Amin ${ }^{4}$ \\ 1,2 Department of Information Technology, GC University, Faisalabad \\ ${ }^{3,4}$ Department of Computer Science, University of Agriculture, Faisalabad \\ 12aayesha.saleem.13@gmail.com, ${ }^{2}$ ranausman88060@gmail.com, ${ }^{3}$ somif8@gmail.com, ${ }^{4}$ misbah.amin293@gmail.com
}

\begin{abstract}
The proper definition of intelligence is not widely known and describable within some selected words till now. There is a great controversy on its definition because generally people have not enough knowledge about it. Computational Intelligence is a subset of Artificial Intelligence and based on particular six approaches. These are Fuzzy Logics, Probabilistic Mechanisms, Natural Swarm Intelligence, Neural Networks and Evolutionary Computing. Traditional artificial intelligence use to develop intelligent systems that require proper and comprehensive information about some task to perform. But numerous real-world systems cannot provide exact and complete information about real-world phenomena. On the other hand, the main concern of Computational intelligence is to design intelligent systems that can be able to make decisions on uncertain or ambiguous information and now this becomes basic future system's need. Both subjects AI and CI have their own importance, but we can analyze that as future needs more intelligent systems, so it required more work, research, understandings and knowledge for computational intelligence. We conduct a survey and meet results that even students of master's degrees not even know about the term "computational intelligence". Therefore, this paper proposed that computational intelligence should be an integral subject of courses as enhancement of artificial intelligence related to at least engineering and computer related fields. It will provide knowledge to students and rise their interest for computational intelligence and encourage them to do work to build more intelligent systems that will be able to deal real word problems in future.
\end{abstract}

Keywords: Computational Intelligence, Academic Courses, Artificial Intelligence, Future Needs, Real World Problems.

\section{INTRODUCTION}

Today and with the passage of time the usage of machines is increasing rapidly. Moreover, the people want their systems faster and more efficient. In past people used technology according to their needs but now the technology becomes the basic need as well as passion of the people. Nowadays people believe that the systems take better decision in their tough situations rather than their own minds. People start to trust on machines than any other person to take solutions of their problems. The accuracy and reliability of the system increasing day by day, But unfortunately almost $60 \%$ people today have their attentions towards development without using the tools or algorithms of Intelligence [1]. The people are not aware that their work can be much better and accurate if they use intelligence modules in their soft wares.

We note that one of its main reasons is the low level of learning in graduate students. According to a survey, only $63 \%$ of students in the areas of computer science and engineering know artificial intelligence, even in the last year of their degree Up to a point, artificial information is used as a major topic in computer studies in a semester, but this period of time is not enough to understand the broader term and its modules [2]. There is a need to continue learning for at least another semester, since the category of internal information known as computational information becomes an important subject for computer and engineering degrees. AI and CI have their own importance in different areas, such as AI at the hardware level, such as REBOTICS and Computational Information at the software level, such as Logics [3] or the implementation of Swarm information, etc.

In this work our much emphasis is on the Computational Intelligence [4], since with AI studies CI should also be taught for the students. It is a mandatory step if we wish to see more intelligent and more precise systems to compete with future needs and more research in computational intelligence domain. This is the only way to guide and motivate the students to start work with their components and make their systems more intelligent to generate improvements in future systems.

\section{DEFICIENCY OF ACQUAINTANCE ABOUT CI IN STUDENTS}

It is seen that students of postgraduates read and learn variant subjects through-out their degree coverage. If talk more precisely about students relate to computer science and engineering filed, they taught about programming related subjects, networking, cyber security, databases 
management, industrial management, etc. No doubt, these subjects are compulsory for basics but at higher levels in their degree there must include some advance subjects. A lot of work had done on web programming, simple electronics, software developments, etc. Now future demands something more interactive, something more helpful for human beings [5]. If we discuss an example of a refrigerator, many people had a great work for its design, size, compressors quality, voltage management abilities, use less power capabilities but provide better cooling, etc. but now innovation is required. If we look towards websites, more interactive, dynamic, and beautifully designed and having a lot new features of linking and security established but same, innovation is still required [6]. Now it's a point of realizing that if we taught our students the same courses or same techniques then how they will be able to do something new or innovative? Rather than modern designing or features in websites, devices or systems we also heavily need about intelligence. There are many domains present to fulfil the need of future systems as artificial intelligence, robotics, machine learning and computational intelligence. Artificial intelligence is included in computer science course. It is a very vast field and it is not possible to cover all of its aspects in just one semester [2].

This paper presents the results of a survey conducted by post graduate students and asked some questions about computational intelligence and artificial intelligence. This survey shows the bitter results that $37 \%$ students of post graduate students not even know about an important term computational intelligence or also about artificial intelligence before reading the survey paper provided information. Remaining 63\% students read about just artificial intelligence in one semester of their degree and even not listen the word computational intelligence before.

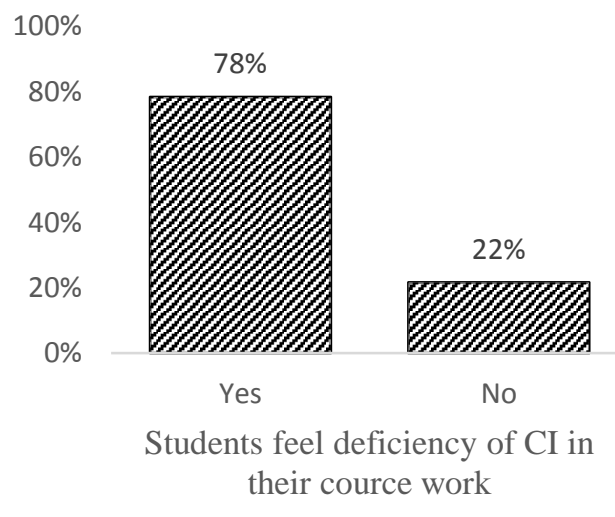

The upper graph shows results of survey conducted from students of final year related to computer science and engineering field. The students asked through survey paper about what they feel about CI. They were asked about working in CI domain as they belong to computer and engineering field of study, then $78 \%$ students answered as (Yes) and 22\% students marked (No). These figures clearly describe students take interest and want to get knowledge about computational intelligence after artificial intelligence in their learning at post graduate studies. It shows interest of students and passion to build advance and intelligent systems in future.

\section{APPLICATION AREAS OF COMPUTATIONAL INTELLIGENCE}

The usage of computational intelligence approaches increases gradually every day. In these days researchers and engineers are having a great attention to compete with their daily tasks of technology by examine natural intelligence [7]. Some of present works of computational intelligence applications consider in order to explain our recommendation. Add account of these applications students need to be aware of computational intelligence to contribute their work in upcoming days. CI is supported and used in combination with its other related terms like machine-learning [8], artificial intelligence (AI) and evolutionary computation [9], etc. Like a present and future requirements more intelligent and precise systems that can be work with ambiguous logics or indeterminate conditions and provide suitable outcomes, improves the usage and significance of computational intelligence. These techniques have been broadly involved in many systems and application domains, e.g., signals processing [10], automatic power control [11], industrial electronics [12], consumer electronics [13], restoration of Half-Toned Color-Quantized images by using particle swarm optimization [14], Support vector machines [15], robotics, stock exchange, finance [16], manufacturing systems [17], etc. The following content will briefly describe about current and vast areas of computational intelligence applications all over the world. It would be enough to show the importance of its learning.

\subsection{Image Processing}

Nowadays images playing important role in human life to generate many types of information. Many of applications relates to computer technology, engineering applications, and scientific studies using image processing to understand different phenomena [18]. The approaches of computational intelligence such as neural networks, fuzzy systems, and evolutionary algorithms are very helpful in decision making processes, information processing and knowledge management [19]. Computational intelligence will play important role to solve several engineering problems in upcoming years. Image processing systems often facing difficulties when dealing with noisy images or having distortions 
problems [20][21]. Computational intelligence approaches provide solutions to accommodate these issues and address problems of real-world image processing in efficient way [22].

\subsection{Intrusion Detection System (IDS)}

The Intrusion Detection System basically used to detect harmful software or malicious codes in computer systems to retain their security consistent. The ratio of cybercrime increased in past decades. To minimize these problems intrusion detection systems, play their vital roles [23]. Different types of approaches are used to protect computer systems from damage. The process of prediction in many intrusion detection systems can produce false notifications based on irregularities. But the use of fuzzy logics, the ratio of false notification rate can be minimized. By using the combination of current fuzzy logic and genetic algorithm techniques, it becomes easy to define regular and irregular behaviors of malicious codes in computer systems. These are the focused of current development efforts and the solution of the Intrusion Detection System [24] problem to actual intrusion detection systems.

\subsection{Bioinformatics}

The progress of bioinformatics is caused by the interaction of it with other fields. Development of bioinformatics need for science, computer, and programming result [25]. In this account, computational intelligence provides many methods, tools, computer algorithms, and programming solutions. As, the need of processing complex problems with high speed processing power and in more careful manner, bioinformatics community provided many different paradigms [26]. Among them, computational intelligence has proved actual solution as nature-inspired computational techniques can be used to generate patterns from large amount of data. Methods like Artificial Immune Systems [27], Neural Networks [28], Evolutionary Computing [29][30], Fuzzy Logic [31], Hidden Markov Models [32], Bayesian Networks [33], Rough Sets [34], Support Vector Machines (SVM) [35] and Swarm Intelligence [36] all have been applied to bioinformatics.

\subsection{Games}

Computational intelligence methods now widely use in gaming purposes instead of old-fashioned artificial intelligence This approach can be used to construct useful characters in current video games, and it can be a foundation to the evolution of games based on machine learning. Evolution can be led by human experiments and research, allowing the developer to manage the kinds of solutions that emerge and inspire the behaviors and appear as an intelligent player to the human player. These types of techniques allow constructing new games that will be more attractive and entertaining than present games, and those that can serve as training environments for players. Techniques [38] developed in these types of games can also be applicable in other related fields, like robotics, prediction of feed grain, Genetic algorithms, resource optimization, and intelligent assistants etc.

\subsection{Accident Control}

It is possible to control automobile accidents if the exact calculations about distance, speed, force of automobiles can maintain and calculated at some appropriate timings [39]. For this purpose, accident prediction models are used in road safety analysis. Computational intelligence is used in many real-world applications, especially when results and data are not same all the time and changes many times. The use of fuzzy controller algorithms [40] decreases the system error. Which means that accident can be minimize up to $100 \%$ using this algorithm. Collision can avoid by using those algorithms to adjust the fuzzy parameters [41].

\subsection{Design Sensor Networks}

Many CI techniques that have been applied to each type of network. Wireless sensor networks face many challenges, caused by communication failures, storage uncertain data, computational issues and limited supply of power. Patterns of computational intelligence have been used by some past years to solve several challenges like data aggregation [42], task scheduling, data fusion, energy routing, security issues, prime distribution and localization. CI mechanisms provide useful approaches that can exhibit intelligent behavior of systems in complex and dynamic environments [43]. CI approaches bring flexibility, self-governance behavior, and power against changing topologies of sensor networks and communication failures.

According to fresh survey we conducted from students, there are five major fields where they want to use CI modules in future. Students were asked to write names of some systems they feel need for more advancement using AI and CI modules to be implemented. According to their answers we can generally nominate five fields and the percentages according to frequency of chosen fields.

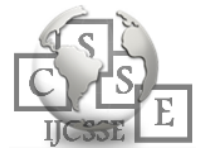




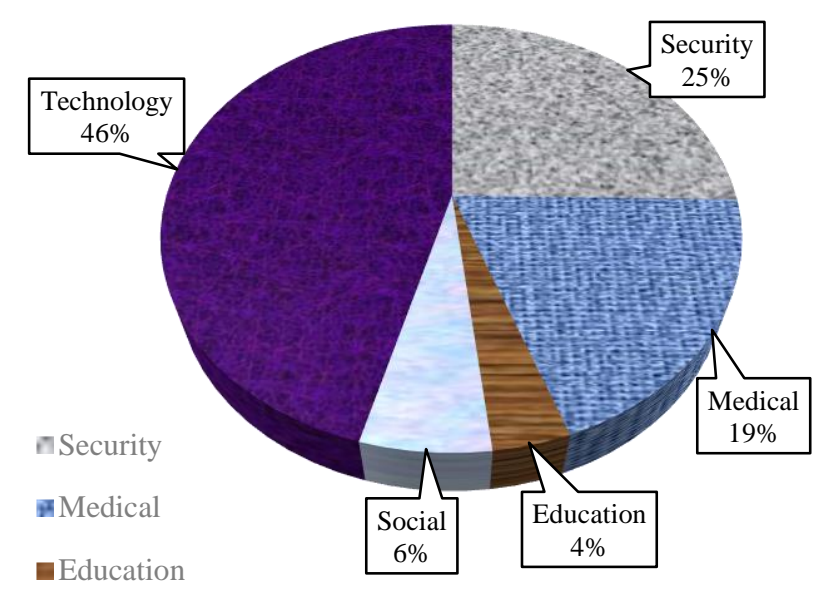

ॠSocial Frequency of selected fields for future systems by students

\section{RELATION BETWEEN ARTIFICIAL INTELLIGENCE AND COMPUTATIONAL INTELLIGENCE}

In the previous centuries we have made enough systems that work according to our instructions. But it is the need of new century to make systems that can take decision also. They will totally independent and take their decisions according to their perception against the environment. AI is mostly based on hardware but In Computational intelligence the concentration part is mainly on the Logics [44]. AI basically used for robotics type products, but CI is based on pure logics like Fuzzy Logic

These technologies decrease human struggle. Now in many industries, people are using these technologies to develop machine slaves to perform the different movement. Using the machine for the work rapidity your procedure of doing work and give you a precise result. Many systems are made which have the following properties:

1. Think like human

2. Act like human

3. Think rationally

4. Act rationally

Because of these properties [46], many systems are developed that named as Expert systems. Some applications of Artificial Intelligence [47] are follows:

1. Smart Bomb's

2. Remote control camera systems directed to proposed object.

3. Automatic drone aircraft

4. Fly missiles of military missions

5. Lunch weapons from a distance
6. Decoding of secret codes

7. Advance weather modeling etc.

The Artificial Intelligence Subject continues to be afflicted by what can only be delineate as bold promises for the future syndrome, frequently performed by researchers who should understand finer. Artificial Intelligence is a major filed in robotics and general science which designed and programmed in such a mean that the systems can think and act rationally and better than human [48]. While uninvolved estimation can point to tactile benefaction over the past fifty years like as automated theorem Evaluation, games policies, Prolog high-level languages, automatic speech recognition, humanoid robots, mobile robot way planning, unmanned vehicles, Natural Language Processing, data mining, and more.

Artificial Intelligence changes the importance of systems nowadays. Life is altered by AI because this knowledge is used in a wide area of daily facilities. AI is proceeding as a major subject at some extent to bachelor level. Because of it many students are making their products in this field whereas they have to face many problems related to algorithms and AI rule-based languages. It should include Computational Intelligence which is also a category of Artificial intelligence to provide better understandings of this domain and reduce the problems of students and encourage them to develop innovations for upcoming technologies [2].

\section{GUIDANCE AND PLATFORMS FOR STUDENTS IN PAKISTAN}

Based on our research there is limited number of teachers in universities that had some work done in machine learning, artificial intelligence or robotics. In Pakistan there are just all around about 50 lecturers present those have a little research and working with respect to these fields.

Not Too long-ago Pakistan launch the first Information and Artificial Incubation Advisor in Lahore [49] based in Singapore. almost 10 months earlier the initial hatchery record in Pakistan held. To improve normal civil service and improve the infrastructure of various sectors of government He will play an important role in Pakistan. He is presently going to Singapore and in the future, he is also going to Dubai and Mumbai. The main concern of ADDO results [50] is to enter financial facilities, recover smart cities for better, safer and cheaper transportation, medical problems and the microinsurance scheme driven by AI. for Asian producers [51].

This will provide support for technology and job opportunities for freshly graduate students but only if our students have certain skills and learnings about artificial intelligence, computational intelligence, machine 
learning or robotics, etc. ADDO AI will also provide opportunities to students to perform the work for the industrial issues of Pakistan and to establish the ever-best solutions of such problems.

Students relates to computer science and engineering filed having interest in the domain of intelligence and want to learn about computational intelligence at great impact. According to our survey $44 \%$ students read AI and want to continue their learning of these types of subjects as Computational Intelligence and 30\% students did not read AI subject in their course subjects but desiring to learn intelligence modules for systems.

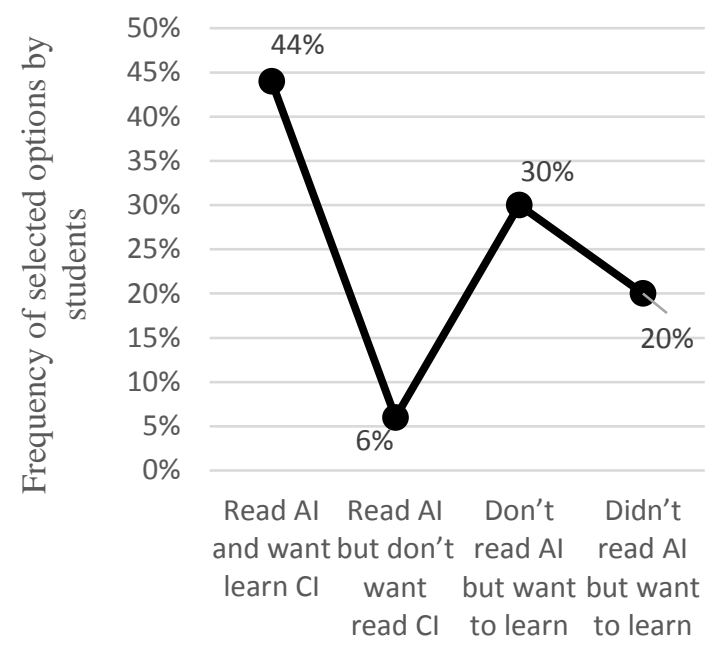

\section{CONCLUSION}

A current, research is introduced in this paper to prepare application of intelligent computing theories and strategies in academic career of the students, by making a part it as major subject. By conducting a survey on Computational Intelligence as adding it a major subject at graduation level we got different responses from students belonging to computer and engineering fields. According to the survey $78 \%$ students choose that it must be an integral part of their course study. Most of them answered for a question about scope of computational intelligence that it is the need of modern age and upcoming generations.

Some of the features, needs and capabilities of the Computational Intelligence are mentioned as Computational intelligence may help engineer at project definition in order to get design purposes. Knowledge in future engineering projects is defined in this paper as placing some elements from human abilities in a cybernetic space [52] to care responsibilities in the progress and tender of products. While authoritative, sometimes extended correction required by machine learning systems can be tough for new users.
Most of the students reacted that it is much tough for them to understand the machine learning algorithms because during their graduation study period only one subject is taught named Artificial intelligence, which doesn't meet their deficiency to understand the algorithms like Fuzzy logic, neural networks, etc. The selection of the processes, the difficulty of the operations, the search of limit space, and the understanding of the outputs in fleshly terms are some of the problems one student must face when using machine learning methods after completing their studies and try to do something in industry.

By adding Computational Intelligence as a major subject at graduation level helps the students to make their FYP's (final year product/project) by involving smart Intelligence modules so that may their product make place in the market at better level. Only time can prove that, this step will be helpful in future as many research articles on CI that will help to upgrade the technology and many other aspects of it.

\section{REFERENCES}

[1] Badan Penyuluhan dan Pengembangan SDM Pertanian, 2015. Pelatihan Teknis Budidaya Padi Bagi Penyuluh Pertanian dan Babinsa: pemupukan. Pusat Peltihan Pertanian, Jakarta.

[2] M. Hidayanto, 2014. "Analisis Tanah Tambak Sebagai Indikator Tingkat Kesuburan Tambak". [Online]. Available:

http://repository.pertanian.go.id/handle/123456789/2039 [Accesed: 17 Maret 2018]

[3] Lowe, D.G. 1999. Object Recognition from Local Scale-Invariant

[4] Features, Canada, pp. 1, 2, 3

[5] Lowe, D.G, 2004. Distinctive image features from scale-invariant keypoints. International Journal of Computer Vision.

[6] Kumalasanti et al, 2015. Identifikasi Tanda Tangan Statik Menggunakan Jaringan Saraf Tiruan Backpropagation Dan Wavelet Haar. Simposium Nasional. Yogyakarta.

[7] Koeshardianto, 2014. Pencocokan Obyek Wajah dengan Metode SIFT (Scale Invariant Feature Transform). Jurnal Ilmiah NERO Vol. 1 No. 1. Madura.

[8] Y. P. Wiharja,2014. "Pemrosesan Citra Digital untuk Klasifikasi Mutu Buah Pisang Menggunakan Jaringan Saraf Tiruan" IJEIS(Indonesian J. Elektron.Instrum.Syst.), Vol.4, No.1, Apr. 2014, pp. 57 68. [Online]. [Accesed: 17 April 2017]

[9] Hermantoro, 2011. Aplikasi pengolahan Citra Digital dan Jaringan Saraf Tiruan Untuk Prediksi Kadar Bahan Organik Dalam Tanah. [Online]. Available: http://www.instiperjogja.ac.id/download/jurnal/CITRAJST-BO.PDF. [Accesed: 17 Maret 2017]

[10] M. B. Bodaghabadi, J. M. Casasnovas, M. H. Salehi, J. Mohammadi, I. E. Borujeni, N. Toomanian, and A. Gandomkar, 2015, Digital Soil Mapping Using 
A. Saleem et. al

Artificial Neural Networks and Terrain-Related Attributes, Pedosphere.25(4): 580-591.. [Online]. Available: $\quad$ https://doi.org/10.1016/S10020160(15)30038-2 [Accesed: 4 Juli 2017]

[11] H. Ramchoun, M. A. J. Idrissi, Y. Ghanou, M. Ettaouil, 2015, Multilayer Perceptron: Architecture Optimization and Training, Pedosphere.25(4): 580-591. [Online]. Available: $\quad$ https://doi.org/10.1016/S10020160(15)30038-2 [Accesed: 10 Mei 2018]

[12] Kapur, S., dan Thakkar, N., 2015. Mastering OpenCV Android Application Programming: Master the art of implementing computer vision algorithms on Android platforms to build robust and efficient applications. Packt Publishing Ltd, Birmingham, pp. 1

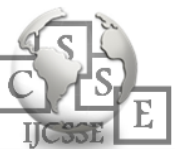

